\title{
How to Improve Employee Proactive Innovation Behavior
}

\author{
Danyang Wang, Lu Ma \\ School of Guangxi University of Science and Technology, Liuzhou, Guangxi, China; \\ 964216798@qq.com
}

Keywords: Shared leadership, proactive innovation behavior, self-efficacy, affective commitment

\begin{abstract}
Active for the enterprise, enhance employee innovation behavior to improve innovation performance, and to lay a solid foundation for the organization's long-term development, and Shared leadership style will help to enhance the staff's initiative and enthusiasm. This study is based on social exchange theory and social cognition theory, and puts forward some Suggestions for improving employee proactive innovation behavior from the perspective of cognition and emotion.
\end{abstract}

\section{Introduction}

Active for the enterprise, enhance employee innovation behavior to improve innovation performance, and to lay a solid foundation for the organization's long-term development, and Shared leadership style will help to enhance the staff's initiative and enthusiasm. In the fierce market competition environment, if just according to the management of judgment and decision making, and the lack of team sharing, mutual responsibility, active atmosphere, easy to miss the good opportunity, not form a scientific and efficient solutions, or behind rivals, leading to the team at a disadvantage in market competition. Therefore, it is crucial to improve the employee's initiative.

\section{Theoretical Basis}

\subsection{Social Exchange Theory.}

At the beginning of the 21 st century, through the exchange theory summarizes, Turner think the actors, on the basis of setting goals, in kind or other forms of exchange of objects for pay, to accept the payer will be return in some physical or other form, actors and eventually accept the payer agreed, to realize the process of exchange is the social exchange. In addition, Chinese scholars ji-hong wu (2006) by combing the social exchange theory related literature at home and abroad, the social exchange theory is divided into staff and organization, interpersonal social exchange theory and social exchange theory of reciprocity.

Employees and organizational social exchange theory by discussing the relationship between the employees and organization, clear organization for employee incentive and their contribution to the organization, and for the employees - the relationship study provides certain theoretical foundation; Social exchange is the exchange between individual employees and the social exchange between employees and organizations. The same is the same: the exchange content of the two is similar, the corresponding resource exchange; They are all in pursuit of exchange of goods; More exchange content embodied in adjacent items, such as the organization can be in the form of money and staff of the exchange of services but not necessarily be able to be exchanged with the employee emotions; Whether trust is enhanced by mutual trust requires both parties to determine the performance of the agreement; Both sides need to reach consensus through effective communication. In the process of social exchange, no matter what exchange, the exchange of both parties should abide by the principle of reciprocity.

\subsection{Social Cognition Theory.}

In the 1970s, the American ethology scholar representative Bandura proposed social cognition theory [1]. He believes that in the process of change people's behavior, cognitive factors play a big role, and self-efficacy is one of the main ways of cognitive factors. In addition, he thought the main 
factors, the main body behavior and the relations between and among the external environment is independent each other and influence each other, each other, from the perspective of a new form of human behavior and its mechanism.

The main content of social cognition theory consists of three kinds of interactive determinism, the observation of study and self-efficacy, as follows. The three elements of the three-yuan interaction determinism are the individual factors, the subject behavior and the environmental factors, and the three elements are independent, influence and determine each other. Because people live in a complex environment, social relations and have cognitive and self-regulation, so you can learn by observation of the model, the modified their behavior. Depending on the time period of the learning process, it can be divided into four steps: attention, maintenance, movement, and motive. Social cognition theory suggests that self-efficacy plays a leading role in the behavior of subjects. According to the information sources, there are four types of self-efficacy: mastering the sexual experience, the alternative experience, the persuasion and the state of mind.

\section{Improve Employee Proactive Innovation Behavior}

\subsection{Choose Effective Leadership.}

Implement Shared leadership and focus on the impact of leadership on proactive innovation behavior. Shared leadership team members share rights, make decisions and take responsibility, promote staff active innovation, make employees can cope with the complex flexible organization situation [2]. As a result, the team leader should be applied in the process of management of Shared leadership theories, encourage employees to participate in group decision-making, let the team members in the process, feel their responsibility and team's trust. Here are some things to do:

(1) It is required that employees not only have to keep the quality of their work, but also to make innovations and improve their performance. Quality is the foundation for the job, but innovation is the key. Because innovation helps the team work more efficiently, it enables companies to move in the direction of progress, enabling companies to build in the industry. Therefore, innovation is of great importance to the enterprise and to the country. The ability of enterprise to innovate will be critical in order to enable enterprise products or services to have a market share in competitive market competition. Therefore, in the process of work, management should pay attention to the innovation system and policy, to strengthen the cultivation of innovative ability, leadership and encouragement, and raise the proactive innovation behavior consciousness and behavior of the employees.

(2) Organize team members to discuss, discover their own shortcomings in knowledge sharing, and encourage employees to learn new skills actively. As the diversity of social knowledge with personal skills of specialization, often need to use group discussion, brainstorming, in the form of the team members to share their personal skills at the same time, integrating the knowledge of the team members, strengthen the interaction between the members, in the process of knowledge sharing, finds itself in the lack of knowledge and skills, and through the collective learning or discuss each other methods such as learning new skills, to adapt to the team, the industry and the development of the society. At the same time, leaders should create a good learning environment for team members and conditions, from the material and spiritual encourage employees to learn new skills, and share what they have learned to the team members, so as to keep up with the pace of The Times, the big role in the industry competition, has a place.

(3) Make a reasonable division of labor, let team members increase trust and understanding in cooperation, and reduce conflict between team members. In the process of team development, with the method of reasonable division of labor, let staff in helping each other, democratic decision-making, respect each other in an atmosphere of complete work task, not only can improve the work efficiency, is beneficial to the completion of tasks, but also in the process of work, increase the identity between employees to each other, improve work ability, strengthen the consciousness of cooperation and communication and coordination ability. In addition, it can also inspire ideas in the 
process of communication, which can contribute to the creation of creative consciousness and behavior.

(4) Be good at empowering employees, allowing talented employees to fully appreciate the trust that comes from leadership and collective, and then take the initiative to realize their value in the team. When leadership initiative to subordinates, can not only for the leaders to share part of the transaction, but also their subordinates skills, gradually let subordinates have a certain amount of awareness, actively participate in team work, and bear corresponding responsibility. But at the same time, as a team leader, you have to weigh the rights and responsibilities of your subordinates, and try to ensure that they are equal and fair. For a long time in the past, using the Shared leadership style, can let the staff to the identity of the leadership and team deepen, increase employee self-efficacy, arouse the initiative and enthusiasm of team members, carry out scientific and efficient organization decision-making, promote staff active innovation.

\subsection{Focuses on Employee Self-efficacy.}

Pay attention to the employee's self-efficacy, create a good team atmosphere, and build a bridge to improve employee's initiative and innovation behavior. In the process of team management, leaders need to focus on employee's self-efficacy and timely communication with the staff at the completion of the difficulties encountered in the work of, reduce staff by reason of innovation failure brings frustration[3]. In addition, the leader should strive to create a good team atmosphere, improve team cooperation consciousness, let staff feel the support from the team, then enhance self-efficacy employees, promote their active innovation.

(1) Bandura in social cognitive theory put forward by the three yuan in mutual determinism, points out that with the change of the people's cognition and behavior, the environment will also be affected by the change, but change after the environment also have a certain influence on people's behavior. On the one hand, leaders can create a good team atmosphere and have a good external influence. Team can, for example, from the material, spirit and system on multi-level, diversified, to build a good team culture, team model demonstration effect, build unity love, positive team atmosphere, and so on. On the other hand, want to notice to employees to improve their own quality, including the physical quality, professional quality and moral quality aspects of content, so as to improve the cognitive level of staff and team as a whole, let more team members in theory and practice to master relevant skills, better long-term development contribution strength for the organization. At the same time, the leader can organize team members more relevant skills contest, let more people know themselves in the form of competition, digging themselves, to further improve the staff's subjective initiative and related skills, ultimately achieve the goal of competing to promote the development, improve the staff's self-efficacy, make employee behavior under the cognitive and environmental factors influence each other be improved.

(2) Based on bandura's theory of observational learning, it is known that let employees in theoretical study and practice in the process of ascension, to observe the way of others, help staff skills improve accordingly. Therefore, the team can conduct regular training activities, and in training activities, pay attention to whether the training content is consistent with the needs of most employees; whether the training method will be effective in stimulating the learning initiative; whether the training effect can achieve the intended purpose. In addition, the team can also combined with the working content, evaluation of outstanding employees, and in a variety of publicity in the form of publicity, such as conducting seminars, report work experience and so on, completes the model demonstration effect, let more people can see their glorious deeds, and the ability to learn good staff quality, the behavior, the quality as embodied in the daily life and work. In recognition of outstanding employees, we should also punish the employees who violate the rules and regulations. Through theoretical study and practice improvement, it can improve the employee's skill level and enhance the employee's self-efficacy, which is beneficial to the employee's proactive innovation behavior.

(3) According to bandura's theory of self-efficacy, the number of successful people is positively correlated with self-efficacy. As the number of success increases, the experience increases, and the ability of the person's self-confidence and problem solving increases, which in turn increases the 
sense of self-efficacy. Leadership when arranging work, therefore, should be combined with the staff's ability level, arrange corresponding work difficulty, and in the process of completing the task, employees should be properly give employee corresponding advice, let employees can finish the work efficient. At the end of the work, objective evaluation should be made on the completion of the work, and in the evaluation, it is important to be aware of the advantages of the employee and help the employee to improve his confidence. In addition, positive attributions help employees improve their sense of self-efficacy [4]. The reasons, the result of the employee's work to bring success to active, its own efforts, actively look for positive aspects, such as efficient solutions to lead employees to believe that through their own efforts to bring the work successfully completed, and improve the staff's self-efficacy and the ability to work.

\subsection{Strengthen Employee Emotional Commitment.}

Strengthening the employee's emotional commitment to improve the impact of Shared leadership on proactive innovation behavior [5]. On team has higher recognition ability of the staff, to meet its own interests and collective interest's conflict, tend to the collective interests first, initiative to help the team the crossing obstacle, to complete the goal, and can help to achieve Shared leadership of the team. In addition, often supported by other members of the team, the encouragement from the leadership or the collective, or help on the level of knowledge, let the members feel he is valued in with the efforts of the team and for sure. In this supportive environment, it is easy to motivate employees to take responsibility and initiative, and team members are more likely to accept and use Shared leadership styles. Existing studies have shown that employees' emotional commitment to the risk perception of reward, the distribution of fairness, and organizational trust can affect the employee's emotional commitment. As a result, leaders should pay attention to the fairness of distribution, and let employees perceived from the team and the trust of the leadership, get the corresponding returns, in order to improve the employee's emotional commitment.

\section{Summary}

Shared leadership team members share rights, make decisions and take responsibility, promote staff active innovation, make employees can cope with the complex flexible organization situation [95]; Leaders to create a good team atmosphere, improve team cooperation consciousness, let staff feel the support from the team, then enhance self-efficacy employees, promote their active innovation; Strengthen the employee's emotional commitment, make the team have a higher sense of identity to the team, and help employees to innovate.

\section{References}

[1]. Smedslund J. Bandura's theory of self-efficacy: A set of common sense theorems [J]. Scandinavian Journal of Psychology, 1978, 19 (1):1-14.

[2]. Zhou W. When does shared leadership matter in entrepreneurial teams: the role of personality composition [J], International Entrepreneurship \& Management Journal, 2014, 12 (1): 1-17.

[3]. Gerard H. Seijts, Gary P. Latham. The Effect of Commitment to a Learning Goal, Self-Efficacy, and the Interaction between Learning Goal Difficulty and Commitment on Performance in a Business Simulation [J]. Human Performance, 2011, 24 (3):189-204.

[4]. Zhang X. Linking empowering leadership and employee creativity: the influence of psychological empowerment, intrinsic motivation, and creative process engagement [J]. Academy of Management Journal, 2010, 53 (1):107-128.

[5]. Lam W, Snape E. Feedback-Seeking Behavior and Leader-Member Exchange: Do Supervisor-Attributed Motives Matter? [J]. Academy of Management Journal, 2007, 50 (2):348-363. 